\title{
Study on Extraction Technology of Total Flavonoids from Alpinia officinarum Hance
}

\author{
Shaodan Peng ${ }^{1, a}$, Yuan Yuan ${ }^{1, b}$, Jihua Li $i^{1, c}$, Xiaobing Huang ${ }^{1, e^{*}}$ \\ ${ }^{1}$ Agricultural Products Processing Research Institute, Chinese Academy of Tropical Agricultural \\ Sciences, Zhanjiang 524001, China;
}

a282387502@qq.com, bJobyuanyuan@qq.com, cfoodpaper@126.com, ehuang5102@hotmail.com

\begin{abstract}
Keywords: Galangal, Flavonoids, Extraction
Abstract. Alpinia officinarum Hance, one of the local herbs in Guangdong, has the rich content of flavonoids and is one of the most commonly used traditional Chinese medicines for the treatment of gastrointestinal tract regulation, smooth muscle spasmolysis, immunoloregulation, antioxygen, tumors, diarrhea, and diphenylheptanes. At present, the main extraction methods of Alpinia officinarum Hance is organic solvent extraction. To obtain the optimum extraction conditions of Alpinia officinarum Hance flavonoids, this study is on the basis of the references, using Ultraviolet spectrophotometric method to measure the content of flavonoids in Alpinia officinarum Hance to explore the ethanol concentration, extraction temperature, extraction time, the solid-liquid ratio and the extraction times in the effects of galanga flavonoids. The experiment found that the opimal extraction condions were as follows: the concentration of $40 \%$ ethanol, extraction temperature 70 ${ }^{\circ} \mathrm{C}$, the solid-liquid ratio of 1:20, extraction time $3 \mathrm{~h}$, extracting for 1 time. Under these conditions, the extraction rate of Alpinia officinarum Hance flavonoids could be as high as $1.40 \%$, namely 14 $\mathrm{mg} / \mathrm{g}$.
\end{abstract}

\section{Introduction}

Galangal, which belongs to dicotyledonous zingiberaceae plants, alias: galanga, small root ginger, bergamot, the cylindrical roots are red brown or dark brown of the surface, and describing a longitudinal wrinkles and grey brown wavy link, toughness, not easy broken, fragrant air, spicy taste. Galangal is located in leizhou peninsula of Guangdong and Hainan, Guangxi, Yunnan, Taiwan and other places. Galangal sell well at home and abrosd with its unique health care function and medicinal value. With the increase of the international market demand for galangal, galangal acreage is rising year by year. Galangal is one of the traditional medicine and food resources, has a warm stomach, wind, cold, pain, regulating the flow of qi. It commonly used to treat stomach cold, belching swallow acid, vomiting at clinical [1]. Modern pharmacology study shows that galangal also has antiviral, antioxidation, antitumor, antibacterial, gastrointestinal bleeding, ulcer, gastric mucosa protection and so on [2].

Galangal active ingredients include essential oil, diphenyl heptane, glycoside, flavonoids, styrene acrylic factor, etc [3]. And the flavonoid is the most important active ingredient. The research shows that flavonoids has analgesia [4], inhibit the ileum contraction movement [5], and antioxidant effect [6] . As we known the flavonoids are widely used in medicine, cosmetics, food and other industries. The flavonoids extracting promoted the comprehensive utilization of galangal.

At present, the extraction method of flavonoids were the organic solvent extraction method; microwave extraction method; supercritical extraction method; the ultrasonic assisted extraction. And the detecting method of flavonoids were spectrophotometry, paper chromatography, thin-layer chromatography, polarography, gas chromatographic method, high performance liquid chromatography, capillary electrophoresis[7]. The ethanol extraction method has reliable, stable, 
low cost, operability and feasibility of industrialization. The galangal was the materials of the test, the ethanol was the extraction of organic solvent, and the content of flavonoids was determined by ultraviolet spectrophotometry. On the basis of this, uniform design was used to get ideal extraction method. Orthogonal experiment was adopted, the effects of concentration of ethanol, temperature of extraction, time of extraction, and times of extraction were investigated.

\section{Materials and Methods}

Experimental chemicals. Galangal was collected from Longtang Town, xuwen County, Zhanjiang of Guangdong province. Catechin was purchased from Sigma-Aldrich Chemical Co. Ltd., and other chemicals including methanol, sodium nitrite, aluminum chloride, sodium hydroxide was procured from xilong scientific. Additionally, all the chemicals and solvents used in this research were analytical reagents.

\section{Single factor experiment.}

Ethanol concentration. Weigh 10 g galanga powder accurately and add $200 \mathrm{ml} 0 \%, 20 \%, 40 \%$, $60 \%, 80 \%, 100 \%$ ethanol solution respectively. Reflux and extrace for 3 hours under $60^{\circ} \mathrm{C}$. The extract after sucking filtration and rotary evaporation was constant with absolute methanol at a $50 \mathrm{~mL}$ capacity bottle. Take $1 \mathrm{ml}$ extract which should be constant with distilled water at a $10 \mathrm{~mL}$ capacity bottle and the blank solution reaction system should be used as the blank control to measure the absorbance at $510 \mathrm{~nm}$.

Extraction temperature. Extraction for 3 hours under $40^{\circ} \mathrm{C}, 50^{\circ} \mathrm{C}, 60^{\circ} \mathrm{C}, 70^{\circ} \mathrm{C}, 80^{\circ} \mathrm{C}$ and $90^{\circ} \mathrm{C}$ respectively.

Solid-liquid ratio. Weigh $10 \mathrm{~g}$ galanga powder accurately and add it into $200 \mathrm{ml} 70 \%$ ethanol solution according to the solid-liquid ratio which were 1:5, 1:10, 1:15, 1:20 and 1:25 respectively. Reflux and extrace for 3 hours under $80^{\circ} \mathrm{C}$.

Extraction time. Weigh $10 \mathrm{~g}$ galanga powder accurately, add $200 \mathrm{ml} 40 \%$ ethanol solution, and reflux with extraction for $1 \mathrm{~h}, 3 \mathrm{~h}, 5 \mathrm{~h}$ and $7 \mathrm{~h}$ respectively under $80^{\circ} \mathrm{C}$.

Extraction times. After one time of extraction and filtration, the $40 \%$ ethanol and filter residue equal to the filtrate volume were put in a round flask. Extracted for the second time and then filtrate again.Place $40 \%$ ethanol and filter residue which are equal to the volume of filtrate in the round bottom flask again. Then Reflux extraction the third time.

Determination of total flavonoid content. The content of total flavonoids was expressed as $\mathrm{g}$ catechin equivalents (CE) per $100 \mathrm{~g}$ of dry weight. In brief, $1 \mathrm{ml}$ of sample was placed in a $10 \mathrm{ml}$ volumetric flask with $4 \mathrm{ml}$ distilled water and $0.3 \mathrm{ml} \mathrm{NaNO} 3(5 \%)$ followed. After $5 \mathrm{~min}, 0.3 \mathrm{ml}$ $\mathrm{AlCl} 3(10 \%)$ was taken into the mixture and $6 \mathrm{~min}$ later, $2 \mathrm{ml} \mathrm{NaOH}(1 \mathrm{M})$ was added and the total volume was made up to $10 \mathrm{ml}$ with distilled water, shaken well. The absorbance of the solution was measured against a blank at $510 \mathrm{~nm}$ with a UV-Visible spectrophotometer (752N, Jingke Industrial Co. Ltd, Shanghai, China). The flavonoid content was calculated using the following calibration curve (1) deriving from catechin as the standard.
$Y$
$0.0035 X$
$0.0038, R^{2}$
0.9999

(1) Where $Y$ is the absorbance, $X$ is the flavonoid content $(\mu \mathrm{g})$. 


\section{Results and Discussion}

\section{Single factor test results}

The effect of different factor on extraction yield of galanga flavone
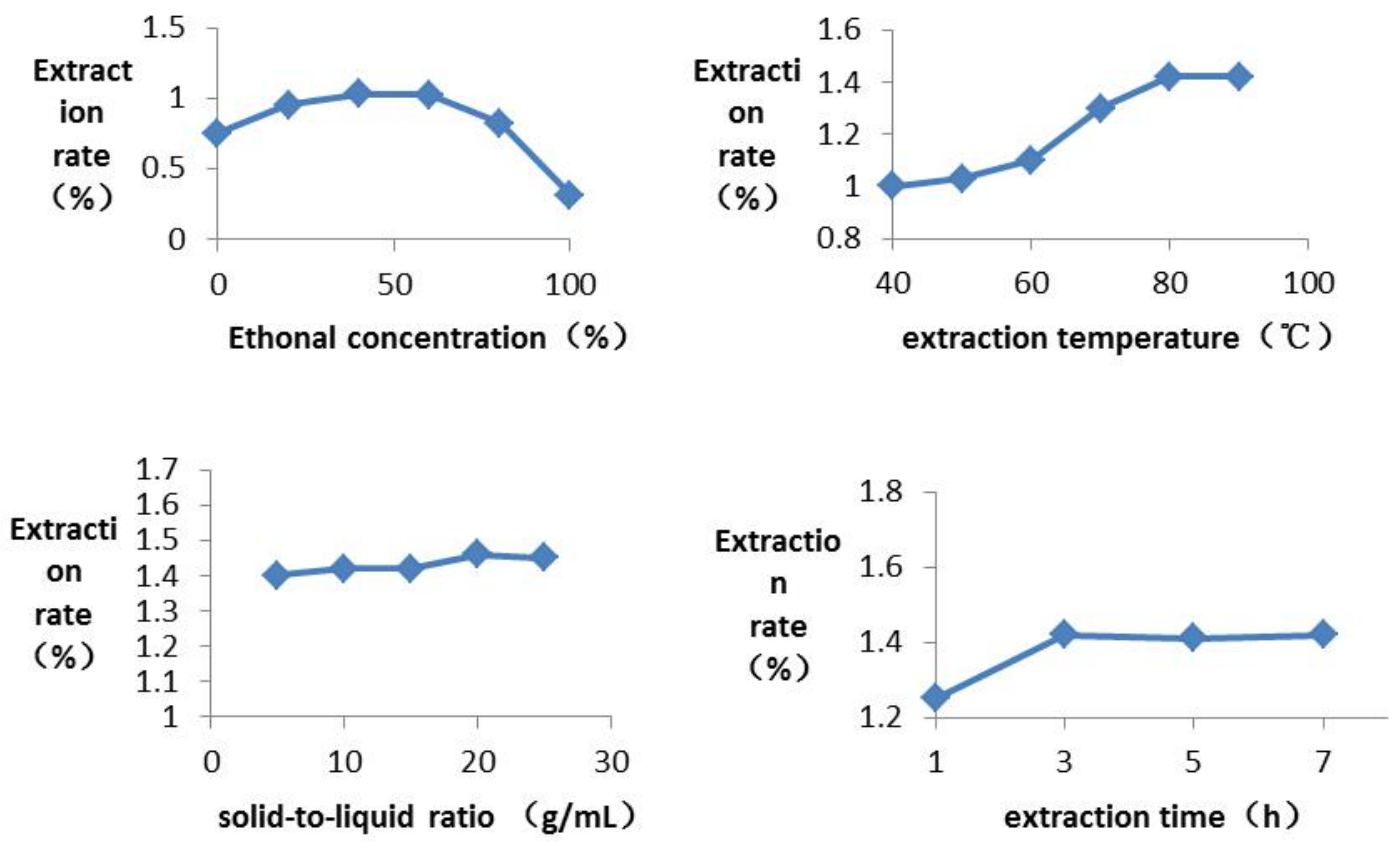

Fig.1 Effect of different factors on the yield of flavonoids

From Fig.1 the yield of flavonoids increased first and then decreased with the increase of ethanol concentration. When the volume fraction of ethanol was $40 \%$, the yield of flavonoids was the highest. The main reason is that flavonoids from galanga is a kind of polyphenol compounds whose structure is the polyhydric phenol compounds containing 15 carbon atoms[8]. The structure has the hydroxyl group which has hydrophilic property while the flavonoid original nucleus is hydrophobic, so the extraction rate will not be too high if it is extracted using strongly polar water or absolute ethyl alcohol with weak polarity only. Therefore, the choice of the $40 \%$ ethanol concentration is appropriate.

The extraction temperature is among $40^{\circ} \mathrm{C}$ to $80^{\circ} \mathrm{C}$, the extraction rate of flavonoids shows an obvious upward trend and the trend of growth tends to be mild at $80^{\circ} \mathrm{C}$ to $90^{\circ} \mathrm{C}$ which suggests that under current conditions, the yield tends to be saturated when the temperature reaches $80^{\circ} \mathrm{C} \sim 90^{\circ} \mathrm{C}$. The reason is that the extraction of galanga is solid-liquid extraction and there are molecular diffusion and convection diffusion during the extraction process. With the increase of temperature, the diffusion velocity of flavonoids from galanga becomes faster and the extraction rate becomes greater. However, when the extraction of flavonoids reaches a saturation state, the extraction rate of flavonoids would not increase with the increase of temperature. Therefore, the suitable extraction temperature is $80^{\circ} \mathrm{C}$.

The amount of flavonoids extracted under the ratio between $1: 5(\mathrm{~g} / \mathrm{mL})$ to $1: 25(\mathrm{~g} / \mathrm{mL})$ are close to each other so the increase of yield is not obvious. But after the ratio of 1:20 $(\mathrm{g} / \mathrm{mL})$, the extraction rate of flavonoids slightly increases. The reason is that the solute has a small mass concentration in the solvent and flavonoids can diffuse into solvent from galanga so the substance dissolved in the solvent increases in mass. Therefore, it is more appropriate to choose the material liquid ratio of $1: 20(\mathrm{~g} / \mathrm{mL})$.

The extraction rate of flavonoids during $1 \mathrm{~h}$ to $3 \mathrm{~h}$ obviously increases and the extraction rate of flavonoids is almost stable after $3 \mathrm{~h}$ which suggest that in a relatively short period of time, the 
powder cannot be completely saturated with water and flavonoids from the deep part of galangal is difficult to be extracted. With the time prolonging, due to the effect of concentration difference, the flavonoids from galanga can be extracted. Therefore, the best extraction time is $3 \mathrm{~h}$.

The effect of extraction times on extraction yield of galanga flavone

Table.1 Effect of extraction times on the yield of flavonolds

\begin{tabular}{|c|c|c|c|}
\hline Times of extraction & 1 & 2 & 3 \\
\hline extraction rate $(\%)$ & 1.43 & 1.49 & 1.45 \\
\hline
\end{tabular}

Table. 1 show that when the extracting times are between 1 to 3 times, the extraction rate of flavone changes a little, which demonstrates that extracting times have little effect on testing results. Thus, the more appropriate is one time.

\section{Orthogonal Experimental Design and Results}

According to the results of single factor experiments, select three factors including ethanol concentration, extraction temperature and extraction time. The orthogonal experimental design is shown in table 2 while the results are shown in table 3.

Table.2 Factors and levels of orthogonal test

\begin{tabular}{cccc}
\hline & \multicolumn{3}{c}{ factors } \\
\cline { 2 - 4 } Level & ethanol concentration $(\%)$ & extraction temperature $\left({ }^{\circ} \mathrm{C}\right)$ & $\begin{array}{c}\text { extraction time } \\
(\mathrm{h})\end{array}$ \\
\hline 1 & 40 & 60 & 1 \\
2 & 60 & 70 & 2 \\
3 & 80 & 80 & 3 \\
\hline
\end{tabular}

Table.3 Experimental design results for orthogonal test

\begin{tabular}{lccccc}
\hline Testing Number & $\begin{array}{c}\text { factors } \\
\text { A ethanol } \\
\text { concentration } \\
(\%)\end{array}$ & $\begin{array}{c}\text { B extraction } \\
\text { temperature } \\
\left({ }^{\circ} \mathrm{C}\right)\end{array}$ & $\begin{array}{c}\text { C extraction } \\
\text { time }(\mathrm{h})\end{array}$ & $\begin{array}{c}\text { null } \\
\text { column }\end{array}$ & $\begin{array}{c}\text { extraction } \\
\text { rate }(\%)\end{array}$ \\
\hline $\mathbf{1}$ & $1(40 \%)$ & $1\left(60^{\circ} \mathrm{C}\right)$ & $1(1 \mathrm{~h})$ & 1 & 1.07 \\
$\mathbf{2}$ & $1(40 \%)$ & $2\left(70^{\circ} \mathrm{C}\right)$ & $2(2 \mathrm{~h})$ & 2 & 1.19 \\
$\mathbf{3}$ & $1(40 \%)$ & $3\left(80^{\circ} \mathrm{C}\right)$ & $3(3 \mathrm{~h})$ & 3 & 1.40 \\
$\mathbf{4}$ & $2(60 \%)$ & $1\left(60^{\circ} \mathrm{C}\right)$ & $3(3 \mathrm{~h})$ & 3 & 1.03 \\
$\mathbf{5}$ & $2(60 \%)$ & $2\left(70^{\circ} \mathrm{C}\right)$ & $1(1 \mathrm{~h})$ & 1 & 1.29 \\
$\mathbf{6}$ & $2(60 \%)$ & $3\left(80^{\circ} \mathrm{C}\right)$ & $2(2 \mathrm{~h})$ & 2 & 0.84 \\
$\mathbf{7}$ & $3(80 \%)$ & $1\left(60^{\circ} \mathrm{C}\right)$ & $3(3 \mathrm{~h})$ & 2 & 0.95 \\
$\mathbf{8}$ & $3(80 \%)$ & $2\left(70^{\circ} \mathrm{C}\right)$ & $1(1 \mathrm{~h})$ & 3 & 0.94 \\
$\mathbf{9}$ & $3(80 \%)$ & $3\left(80^{\circ} \mathrm{C}\right)$ & $2(2 \mathrm{~h})$ & 1 & 0.79 \\
$\mathbf{k}$ 1 & 1.22 & 1.017 & 0.95 & 1.05 & \\
$\mathbf{k} 2$ & 1.053 & 1.14 & 1.003 & 0.993 & \\
$\mathbf{k} 3$ & 0.893 & 1.01 & 1.213 & 1.123 & \\
$\mathbf{R}$ & 0.327 & 0.13 & 0.263 & 0.13 & \\
Priorities of & $\mathrm{ACB}$ & & & & \\
factors & & & & & \\
Optimal plan & $\mathrm{A}_{1} \mathrm{C}_{3} \mathrm{~B}_{3}$ & & & & \\
\hline
\end{tabular}

The order of $\mathrm{R}$ for three factors in table 2 as $\mathrm{A}>\mathrm{C}>\mathrm{B}$ by comparing them with each other. The larger $\mathrm{R}$ shows that this factor has deeper influence on the testing results. In other words, ethanol concentration has the greatest impact on the extraction rate of flavone in rhizoma alpiniae 
officinarum. The second was extraction time while the extraction time has little effect. The analysis reveals that the optimum combination of extraction conditions is $\mathrm{A}_{1} \mathrm{C}_{3} \mathrm{~B}_{3}$, when the ethanol concentration is $40 \%$, extracting for 3 hours under $80{ }^{\circ} \mathrm{C}$. Under this conditions, the extracting rate of alpinia officinarum flavone is $1.40 \%$, which is higher than any groups in the experiment.

\section{Validated test of optimum technique}

Weigh galangal powder for $10 \mathrm{~g}$ and conduct validated test by optimization of conditions $\mathrm{A}_{1} \mathrm{C}_{3}$ $\mathrm{B}_{3}$ according to orthogonal experiment and repeat 3 times. The results are respectively $1.40 \%$, $1.41 \%$ and $1.42 \%$ while the average result is $1.41 \%$, which has no significant difference compared with the extracting rate of flavone under the optimum conditions of orthogonal experiment. Therefore, it proved that optimization of conditions $\mathrm{A}_{1} \mathrm{C}_{3} \mathrm{~B}_{3}$ is the optimal conditions of extracting flavone from rhizoma alpiniae officinarum.

\section{Conclusions}

This experiment discussed the extraction technology of total flavone of galangal and use coloration of aluminum to determine the content of flavone. The results showed that ethanol concentration has the greatest impact on the extraction rate of flavone, the second was extraction time while the extraction time was the last. The optimum extraction conditions of total flavone from galanga are extraction temperature $80^{\circ} \mathrm{C}$, ethanol concentration $40 \%$, extraction time 3 hours, solid liquid ratio 1:20 and extracting time with one time. When conducting validated test by this condition, the content of total flavone from galanga can be obtained for $14.1 \mathrm{mg} / \mathrm{g}$.

Galanga contain abundant flavonoids, and the main constituents isolated from galanga flavone are quercetin, kaempferide, galangin and kaempferol 4'- methyl ether, etc[9]. As the main component of galanga, galangin has anti - tumor activity. At the same time, combining the galangin with traditional chemotherapeutics has possibility to improve and enhance the treatment effect of tumor[10], but the study of anti - tumor mechanism of it is not deep. The experiment studied on the extraction technology of total flavones from galanga by traditional heat reflux extraction in organic solvents. The optimum extraction technology was obtained by single factor experiments and orthogonal experiments, which is favorable for improving the extraction rate of total flavones from galanga. As a result, the purity of galangin can up to $89.39 \%$ [11] by using optimum ways in the ethanol extraction from the root of galanga, which has important significance on the study of enhancing anti - tumor activity of galanga and its mechanism.

\section{Acknowledgements}

This work was financially supported by the Central Public-interest Scientific Institution Basal Research Fund for Chinese Academy of Tropical Agricultural Sciences (No. 1630122016009) and (No. 1630122016010).

\section{References}

[1] National Pharmacopoeia Committee. Chinese Medicine Pharmacopoeia I Department[S]. Beijing: Chemical Industry Press, 2005:202.

[2] Huizhen Huang, Dan Yang. Research on Development of the Chemical Composition and Pharmacological Activity of Alpinia Officinarum. Guangdong Chemical Industry.Vol. 36(2009) No.1, p.77-80. 
[3] Gailian Zhou, Ning Xin, Luliang Huang. Resaerch on Galangal chemical composition, Lishizhen Medicine and Materiamedica Research, Vol, 19 (2008) No.6,p.1376-1378.

[4] Yanjun Yang,Congwei Sha,Xiaojuan Chen,et al.Study on the Analgesic Active Site of Alpinia Officinarum. Guangdong Medical Journal. Vol. 29 (2008)No.8,p.1286-1287.

[5] Chunping Tang, Congwei Sha, Xiaojun Chen. Research on Galangal flavonoids on the movements of rabbit ileum in vitro, Pharmacology and Clinics of Chinese Materia Medica, Vol. 22 (2006)No.5,p.23-25.

[6] Saija A, Scalese M, Lanza M, et al.Free Radical Biol.Med. Vol.19(1995),481.

[7] Yan Zhang, Guojie Cao, Yan Zhang, et al. Research on progress of extraction and determination of flavonoids, Journal of Tianjin University of Science and Technology , Vol. 29 (2008)No.1,p.154-156.

[8] Wei Lv,Linghuo Jiang.Chemical Constituents and Pharmacological Activities of Apinia officinarum Hance.China Pharmaceuticals. Vol. 15 (2006) No.3, p.19-20.

[9] Xianzhang Piao, Guiwu Xiao, Lianquan Gu,et al. Resaerch on Galangal chemical composition, China Pharmaceuticals. Vol. 23 (2000) No.2, p.84-86.

[10]Wenjing Zhang, Qilai Huang, Zichun Hua, et al. Research on biological activity of galangin, Chinese Medicinal Biotechnology. Vol. 7 (2012) No.4, p.294-297.

[11]Airong Kang, Ming Yan, Ying Peng, et al. Research on extraction and purification technology of galangin from galangal. Chinese journal of information on traditional Chinese medicine. Vol. 18 (2011) No.5, p.44-46. 